\title{
Phonological representations and the variable patterning of glides
}

\author{
Andrew Nevins ${ }^{\mathrm{a}, *}$, Ioana Chitoran ${ }^{\mathrm{b}}$ \\ ${ }^{a}$ Department of Linguistics, 317 Boylston Hall, Harvard University, Cambridge, MA 02139,USA \\ ${ }^{\mathrm{b}}$ Linguistics and Cognitive Science Program, HB 6220 Dartmouth College, Hanover, NH 03755, USA
}

Received 5 August 2007; received in revised form 31 August 2007; accepted 2 October 2007

Available online 11 December 2007

\begin{abstract}
We argue that the glides $[\mathrm{j}, \mathrm{w}]$ are not just non-nuclear versions of vowels, but also bear a subsegmental difference, which we propose is due to a feature $[ \pm$ vocalic $]$. This representational difference is integrated into an explanation of why glides may be skipped in vowel harmony, even when other consonants do participate in harmony. In addition, we propose that the glides [j,w] have two Designated Articulators: [j] is both [Dorsal] and [Coronal], and [w] is both [Dorsal] and [Labial]. These representational proposals shed light on a number of phenomena, such as why the glide [j] becomes [k] in some languages, but [3] in others, as well as why the glide $[\mathrm{w}]$ can sometimes become $[\mathrm{m}]$. In short, glides are mentally represented as neither vowels nor consonants, have their own constriction degree, and have two Designated Articulators. The interaction of the logic of abstract binary featural representations together with representational notions such as constrastivity and representational simplification yields this typology of variable patterning.

Published by Elsevier B.V.
\end{abstract}

Keywords: Phonological representations; Glides; Designated Articulators

\section{Introduction}

Our goal in this paper is to propose that glides have two designated Articulator features: [Coronal] and [Dorsal] in the case of $/ \mathrm{j} /$, and [Labial] and [Dorsal] in the case of $/ \mathrm{w} /$. We also propose the re-introduction of a major class feature $[ \pm$ vocalic] in addition to $[ \pm$ consonantal] (see also Padgett, this volume).

The main issue in the phonological representation of glides has been centered around the relevance of distinctive features vs. syllable structure. The syllabic representation proposal, in its

* Corresponding author.

E-mail addresses: nevins@fas.harvard.edu (A. Nevins), ioana.chitoran@dartmouth.edu (I. Chitoran). 
strongest form, claims that glides and vowels are subsegmentally identical and differ only in syllabic affiliation. We argue that the study of glides must encompass and explain patterns in which glides further strengthen to obstruents, as is the case for example in Cypriot Greek /i/ $\rightarrow$ [j] $\rightarrow$ [k] (Kaisse, 1992), or Pulaar /u/ $\rightarrow$ [w] $\rightarrow$ [g] (Paradis, 1987, 1992).

Section 2 presents an overview of the phonetic correlates of the vowel/glide distinction, concluding that constriction degree differentiates glides from vowels. In section 3 , we present the details of our argument that glides must be subsegmentally distinct from vowels, based on representative case studies from Russian, Kyrghyz, and Turkish. Section 4 briefly discusses the representation of glides that are derived from vowels via resyllabification, arguing that resyllabification to syllable margin requires a featural change. Section 5 focuses on the place of articulation alternations that accompany glide strengthening data in Cypriot Greek, Bergüner Romansh, Karuk, and Argentinian Spanish. These alternations pose a challenge for feature geometry models in which glides have only one Designated Articulator. In section 6, we conclude and discuss some of the phonetic correlates one might expect from the proposed featural specifications.

This paper is centered on the representational composition of glides, and as a representational proposal, it is intended to be compatible with both derivational and optimality-theoretic frameworks, and to be translatable into other featural or gestural models. In other words, our goal is to show the importance of the proposed subsegmental composition of glides, without necessarily supporting a specific overall architecture over others. Formalization of derivations is presented in the form of rules interleaved with constraints, following the model of Calabrese (2005), largely to minimize space that would be devoted to introducing the faithfulness constraints that would be necessary in optimality-theoretic tableaux; however, these derivations could no doubt be equivalently formulated in fully-constraint-based models that allow intermediate representations. It is our hope that the conclusions reached here about the articulatory representations of glides can be incorporated into a wide variety of phonological architectures.

\section{Phonetic correlates of glides}

In understanding the phonetic properties of glides, one finds some consensus in the literature as to what is and what is not uniquely characteristic of glides. Maddieson (this volume) demonstrates that geminate glides exist in a number of languages (e.g. Amharic, Tamil, and Trique) and shows that shortened duration cannot be crucial to the definition of glides. Based on phonetic evidence from Maddieson and Emmorey (1985) and Ladefoged and Maddieson (1996), Padgett (this volume) argues that glides and vowels can differ in constriction degree. $/ \mathrm{j} / \mathrm{has}$ a narrower constriction than /i/, a property which in turn makes it more likely to cause palatalization and/or affrication of a preceding consonant than $/ \mathrm{i} / .{ }^{1}$ Hall and Hamann (2006) and Hall et al. (2006) show, for example, that stops become sibilant affricates or sibilant fricatives before high vowels or glides. This is explained by the fact that a stop released through a narrow constriction is turbulent, and the turbulence can be interpreted as affrication or assibilation. If / $\mathrm{j} /$ has narrower constriction than /i/, than stop assibilation is expected to be longer before the glide than before the vowel. Hall and Hamann (2006) find that the friction phase, measured from the offset of the stop release to the onset of the following high front vocoid is significantly longer before / $\mathrm{j}$ / than before /i/ in German and Polish. The aerodynamic explanation of this phenomenon

\footnotetext{
${ }^{1}$ Bateman (2007) provides important characterizations of differences in the patterning of glides vs. vowels in triggering the distinct processes of palatalization and affrication.
} 
was formulated by Ohala (1983). The high velocity of the airflow produced at the release of a stop is maintained longer when the stop is followed by a close vowel than an open vowel. Palatalizing mutations, affrication, assibilation are therefore more likely the greater the constriction degree of the following front vocoid. The feature $[ \pm$ vocalic] is a good candidate for representing this constriction difference. Clark and Yallop (1995) emphasize constriction as the defining articulatory characteristic of glides compared to vowels. Additional evidence comes from Straka (1964), who found that, when segments were produced under increased effort, vowels have less constriction, while consonants (and glides) have greater constriction.

\section{Major class features}

In order to capture the phonetic and phonological differences between glides and vowels on the one hand and between glides and consonants on the other hand, we propose a new featural representation. As vowels and glides differ in constriction degree, we propose that they differ in a feature [ \pm vocalic]. Many authors (e.g. Hyman (1985)) have argued for [consonantal] as the feature that distinguishes vowels and glides; however, since an additional distinction is needed between glides (which we argue may have two Designated Articulators) and consonants (which, in the languages under study here, may not have two Designated Articulators), glides must be [-consonantal]. The representational differences between vowels and glides captured by [consonantal] in models such as Hyman (1985) can thus be translated into differences in [vocalic] in the current model.

$$
\begin{aligned}
& \text { Definitions of features } \\
& {[+ \text { consonantal }]=\text { presence of an occlusion of the free passage of air in }} \\
& \text { the supralaryngeal vocal tract } \\
& {[+ \text { vocalic }]=\text { absence of a narrow constriction among the articulators }} \\
& {[-\mathrm{F}]=\neg[+\mathrm{F}]}
\end{aligned}
$$

Note that the feature $[ \pm$ vocalic] and its definition are distinct from that of Jakobson and Halle (1956), who defined [ \pm vocalic] in such a way as to pair vowels with liquids as a natural class sharing $[ \pm$ vocalic]. This grouping failed to capture certain patterns of natural class behavior, in particular failing to capture the fact that liquids and vowels rarely if ever pattern together to the exclusion of nasals. ${ }^{2}$ However, both glides and vowels are [-consonantal].

$$
\begin{aligned}
& \text { Natural Classes of segments given }[ \pm \text { cons }] \text { and }[ \pm \text { voc }] \text { : } \\
& \text { obstruents }=[+ \text { cons, }- \text { voc, }- \text { sonorant }] \\
& \text { liquids, nasals }=[+ \text { cons },- \text { voc },+ \text { sonorant }] \\
& \text { vowels }=[- \text { cons },+ \text { voc },+ \text { sonorant }] \\
& \text { glides }=[- \text { cons, }- \text { voc },+ \text { sonorant }] \\
& \text { illicit combination: } *[+ \text { cons },+ \text { voc }]
\end{aligned}
$$

\footnotetext{
${ }^{2}$ Schane (1968) proposed that liquids are $[+$ cons, + voc]. The co-occurrence of these features would not be possible given their semantics in (1). Following a reanalysis of Schane's data by Bailey and Milner (1967), [Chomsky and Halle (1968) p. 354] replaced [ \pm vocalic] with the feature [ \pm syllabic] in distinguishing glides and vowels. However, as syllabic nucleihood came to be represented as a structural affiliation to a suprasegmental position (Clements and Keyser, 1983), use of the feature [ \pm syllabic] disappeared, leading to the loss of a subsegmental featural representation encoding vowel/ glide differences.
} 
In addition to the major class features $[ \pm$ cons, \pm voc, \pm son], the manner features $[ \pm$ lateral, \pm nasal], and the laryngeal features of voicing and aspiration, we adopt the proposal, shared by Sagey (1986), Clements (1991), Halle (1995, 2005), Clements and Hume (1995) and Halle et al. (2000), that all segments may include one or more unary-valued Articulator feature(s) (sometimes called the Designated Articulator(s)), which include [Labial], [Coronal], [Dorsal], and [Glottal]. (Importantly, there is no Articulator feature [Palatal].)

Laryngeal fricatives such as $[\mathrm{h}]$ are arguably also [-cons, - voc], as they include a degree of constriction at the glottis. Their designated articulator is [Glottal] and they may be either [ \pm voice $]$.

Given (2), glides form both a natural class with consonants, and a natural class with vowels. The feature $[ \pm$ cons] is still a "major class" feature. [ \pm voc] (which is contrastive for [-cons]): specifies (absence of) constriction. This proposal is for derived as well as underlying glides. Derived glides become [-voc] automatically by virtue of placement outside of a nucleus. We encode this via the inviolable constraint *[+voc]/_ MARGIN, which bans the occurrence of this feature in a syllable margin, and will be discussed in greater detail in section 4.

If $[ \pm$ consonantal] is a feature distinguishing consonants from vowels and derived glides, we expect it to be able to spread like any other subsegmental feature, though, as Kaisse (1992) points out in the following passage, there may be principled reasons for the comparative rarity of this type of assimilation:

"The origin of most assimilations lies in articulatory phonetics. When [place] spreads, we are retaining a physical configuration of the oral articulators. When [nasal] spreads, we are prolonging or anticipating the open position of the velum. And when [voice] spreads, we are, in most cases, maintaining a configuration of the larynx. But [consonantal] refers to any narrowing of the oral cavity at least as narrow as that of a fricative. We have seen consonantality spreading from a labial to a palatal, for instance. No actual articulatory position is being maintained, only the abstract notion of a severe occlusion of the oral cavity". [Kaisse, 1992:330]

To summarize, the feature [ \pm consonantal] specifies the abstract notion of severe occlusion of the oral cavity, while the feature $[ \pm$ vocalic] specifies a relative degree of constriction. In the following subsections we explore phonological patterning that reveals a distinct behavior of glides from both vowels and consonants and supports the independent phonetic basis for these two binary-valued articulatory features.

\subsection{Case studies in which glides $\neq$ vowels, glides $\neq$ consonants}

\subsubsection{Russian: glides delete differently and condition allomorphy differently}

The first source of evidence for a representation in which glides pattern with consonants rather than vowels for one process, but unlike consonants for a second process, may be found in Russian morphophonology. Russian has a rule of vowel deletion before vowels and a rule of glide deletion before consonants. We show how these can be unified using the proposed featural system. The relevant deletion rules are (Jakobson, 1948; Halle, 1994):

\section{Deletion Rules in Russian}
a. $\mathrm{V} \rightarrow \emptyset /{ }_{-} \mathrm{V}$
b. $\mathrm{J} \rightarrow \emptyset /{ }_{-} \mathrm{C}$ 
Verbal derivations (thematic affixes in SMALLCAPS):

(4) $\quad \mathrm{p}$ 'is $+\mathrm{A}\left(\right.$ ('to write') $^{2}$

a. $p^{\prime}$ is $+A+u=p^{\prime} i s ̌ u[1 s g]$ (A truncates)

b. $\mathrm{p}^{\prime}$ is $+\mathrm{A}+\mathrm{t}^{\prime}, 1=\mathrm{p}^{\prime}$ isat ${ }^{\prime}$ [infin.] / $\mathrm{p}^{\prime}$ isal [past-masc.sg]

(5) Čit $+\mathrm{AJ}($ 'to read')

a. čit $+\mathrm{AJ}+\mathrm{u}=$ čitaju [1sg]

b. čit $+\mathrm{AJ}+\mathrm{t}^{\prime}, 1=$ čitat $^{\prime}$ [infin.] / čital [past-masc.sg] (J truncates)

(6) $\quad \mathrm{bol}+\mathrm{E}\left({ }^{\prime}\right.$ to hurt')

a. bol $+\mathrm{E}+$ it $=$ bol'it $[3 \mathrm{sg}]$ (E truncates)

b. bol $+\mathrm{E}+\mathrm{t}^{\prime}, 1=$ bol'et' $^{\prime}$ infin.] / bol'el [past-masc.sg]

(7) $\quad$ bol + EJ ('to be sick')

a. $b o l+E J+u=b^{\prime}{ }^{\prime} e j u[1 s g]$

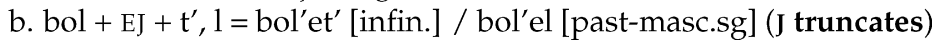

In (4) and (6), the vowel of the thematic suffix deletes before a vowel-initial inflectional suffix. In (5) and (7), the glide of the thematic suffix deletes before a consonant-initial infinitival ending. Given our revised featural system (repeated in (8)), these two rules may be stated as in (9):

(8) obstruents, liquids, nasals $=[+$ cons,-voc $]$

vowels $=[$-cons, + voc $]$

glides $=[-$ cons,- voc $]$

(9) $\quad$ a. $[+\mathrm{voc}] \rightarrow \emptyset /-[+\mathrm{voc}]$

b. $[-$ cons, - voc $] \rightarrow \emptyset /-[-$ voc $]$

Importantly, given that both glides and vowels are [-cons], these two rules can be unified in turn as a single process, namely deletion of "like before like":

$$
[- \text { cons, } \alpha \mathrm{voc}] \rightarrow \emptyset /{ }_{-}[\alpha \mathrm{voc}]
$$

We turn to a second process of Russian morphophonology, the determination of genitive plural allomorphy. While the conditions on the selection of one of the three allomorphs $-e j .-o v, \emptyset$ is subject to certain complexities (see Bailyn and Nevins, 2007), one basic generalization is that the allomorph is $-e j$ after [-back] consonants. Thus, compare (11-a) with the other examples. Surprisingly, however, this allomorph is not chosen for stems ending in the [-back] palatal glide $(11-d)^{3}$

Allomorphy of Genitive Plural Ending in Russian
a. dver'+ej 'door'
b. stol+ov 'table'
c. $\quad$ knig $+\emptyset$ 'book'
d. boj+ov 'fight' (not *boj-ej)

Within the featural representations being proposed here, the statement of this fact is straightforward: this allomorph is limited to stems that end in a [+cons] segment. Thus, although

\footnotetext{
${ }^{3}$ This is not due to a general ban in Russian on glides in adjacent heteromorphemic syllables, which are freely allowed: cf. stat 'ja, stat'joj 'article; nom. sg, instr. sg'.
} 
the palatal glide $/ \mathrm{j} /$ is $\left[-\right.$ back], it is not $\left[+\right.$ cons] (nor is it $[+$ voc $]$ ). ${ }^{4}$ Coupled together, the Russian palatal glide facts necessitate a simultaneous vowel/glide distinction (10) and consonant/glide distinction (11) within the same language.

\subsubsection{Kyrghyz and Turkish: glides escape vowel harmony}

In this section, we will demonstrate that glides are transparent to vowel harmony in Kyrghyz and Turkish and conclude that this fact must be derived from the representation of glides as [-vocalic], coupled with the notion of contrastive feature-visibility of Calabrese (1995). The argument will be that the invisibility of glides to vowel harmony in Turkic cannot come from their syllable position, as other consonants in non-nuclear positions do in fact participate in vowel harmony.

The [-vocalic] behavior of glides is demonstrated by their transparency to vowel harmony in Kyrghyz. Recall that vowels are [+voc, - cons]. The vowel harmony in Kyrghyz is for the feature $[ \pm$ back] and affects all eight vowels in the language.

Kyrghyz Vowel Inventory:
\begin{tabular}{|l|l|l|l|l|}
\hline & {$[-\mathrm{bk},-\mathrm{rd}]$} & {$[-\mathrm{bk},+\mathrm{rd}]$} & {$[+\mathrm{bk},-\mathrm{rd}]$} & {$[+\mathrm{bk},+\mathrm{rd}]$} \\
\hline$[+$ high $]$ & $\mathrm{i}$ & $\ddot{\mathrm{u}}$ & $\dot{\mathrm{i}}$ & $\mathrm{u}$ \\
\hline$[-$ high $]$ & $\mathrm{e}$ & $\ddot{o}$ & $\mathrm{a}$ & $\mathrm{o}$ \\
\hline
\end{tabular}

The operation of [back] harmony is completely systematic in Kyrghyz: it operates from left-toright, being triggered by all vowels, and affecting all vowels, resulting in stem-internal harmony and suffixal alternations. ${ }^{5}$ We demonstrate the alternations in three representative suffixes, each of which have four different forms, depending on the operation of [back] (and also [round]) harmony.

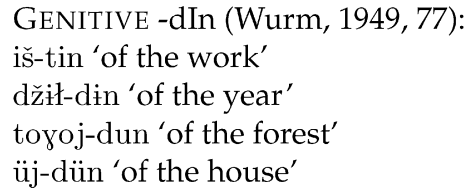

ORDINAL -InçI (Poppe, 1963, 7-8):

beš-inçi 'fifth'

alti-nçi 'sixth'

toguz-unçu 'ninth'

tört-ünçü 'fourth'

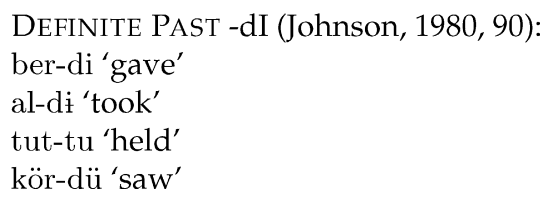

While it is not crucial to the glide/vowel difference whether harmony is modeled as spreading or feature-copying, we opt for the latter for the current discussion. While [back] is copied from left-to-right from the closest adjacent vowel straightforwardly among the Kyrghyz vowels, in which all vowels participate, this behavior is importantly different in roots whose last consonant is the

\footnotetext{
${ }^{4}$ Interestingly, the narrow approximant $v$, a [+cons] segment in its surface form in Russian, does exhibit $[ \pm$ back] contrasts, also conditioning genitive plural allomorphy: $t s e r k v$ ' $+e j$ 'church' vs. $l v+o v$ 'lion'.

${ }^{5}$ Kyrghyz also has a system of [round] harmony, which applies to all vowels, with the exception of the sequence $u C a$, which is allowed See Korn (1969); Vaux (1993) for discussion.
} 
palatal glide /j/, which is phonetically and featurally [-back]. This palatal glide is transparent to [+back] harmony across it:

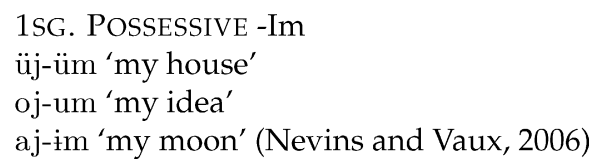

Importantly, the glide is fully transparent: it does not itself undergo harmony (17), nor does it block or initiate harmony across it (18):

$$
\begin{aligned}
& \text { *üựü, *ounum, *oịim } \\
& \text { *oj-üm, *aj-im }
\end{aligned}
$$

Like in Kyrghyz (for which Nevins and Vaux (2006) provide phonetic evidence of the harmonic transparency of glides), in Turkish, the palatal glide is also [-vocalic] and escapes vowel harmony. On the basis of the behavior of other Turkish consonants that do participate in harmony, however, one cannot simply conclude that it is a difference in syllabic nucleihood that distinguishes the harmonically participating vowels from the non-participating glides. Rather, a featural difference, as proposed above, interacting with a principle of contrastive feature-visibility in harmony, will yield the correct cut between participating and non-participating segments.

Unlike Kyrghyz, Turkish has a [ \pm back] contrast for three pairs of consonants: k/k',g/g', $1 / 1$ ' (Clements and Sezer, 1982; Kornfilt, 1997; Levi, 2004) that are contrastive (18) for the feature [back], as shown by the following (near-) minimal pairs:

$$
\begin{aligned}
& \text { Turkish pairs contrasting [+back] and [-back] velars and liquids: } \\
& \text { bol 'abundant' bol' 'cocktail' } \\
& \text { kalp 'counterfeit' kal'p 'heart' } \\
& \text { kar 'snow' k'ar 'profit' } \\
& \text { gaz 'gas' g'avur 'infidel' }
\end{aligned}
$$

\begin{tabular}{|c|c|c|}
\hline usul $^{\mathrm{y}}$ & $\mathrm{usul}^{\mathrm{y}}-\ddot{\mathrm{u}}$ & system- \\
\hline $\mathrm{sual}^{\mathrm{y}}$ & sual $^{\mathrm{y}}-\mathrm{i}$ & question-acc.sg \\
\hline okul & okul-u & school-acc.sg \\
\hline karakol & karakol-u & police.station-acc \\
\hline petrol $^{\mathrm{y}}$ & petrol $^{\mathrm{y}}$-de & petrol-loc.sg \\
\hline $\operatorname{me} \int g u^{\mathrm{y}}$ & $m e \int g u l^{\mathrm{y}}-d \ddot{u}-\mathrm{m}$ & busy-past-1.sg \\
\hline
\end{tabular}

We notate $\mathrm{k}^{\prime}, \mathrm{g}^{\prime}, \mathrm{l}^{\prime}$ as $\mathrm{k}^{\mathrm{y}}, \mathrm{g}^{\mathrm{y}}, \mathrm{l}^{\mathrm{y}}$, respectively. These segments, bearing a contrastive value for [back], participate in back harmony. In the following examples, in which certain roots are "disharmonic", it is always the case that the last contrastive value for $[ \pm$ back $]$ is the one that determines harmony on the suffix. Thus, it is shown that the [-back] liquid $\mathrm{l}^{\mathrm{y}}$ intercepts a [+back] span of vowel harmony, triggering a [-back] value on the following vowel.

The examples in (20) show that the [-back] liquid triggers [-back] harmony in the accusative suffix, even when preceding root vowels may be [+back]. Furthermore, the last two examples of (20) show that the triggering liquid and the suffix vowel undergoing harmony need not be strictly adjacent.

The [-back] value of the accusative suffix in Turkish gets its value by harmony with a preceding liquid, as governed by a single statement (Nevins, 2004): 
Clearly, in [me $\int$ gul $^{\mathrm{y}}$-düm], the $\mathrm{1}^{\mathrm{y}}$ is a closer potential source from which to copy a [back] value than the preceding $u$. Hence, in a leftward search for a value-source from which to copy, once $\mathrm{l}^{\mathrm{y}}$ is encountered, [-back] is copied to the suffix, and the search for [back] is terminated. However, the search for [round] continues, until $u$ is encountered.

A crucial difference between $[-$ back $] / \mathrm{l}^{\mathrm{y}} /$ and $[-\mathrm{back}] / \mathrm{j} /$ is that while there $i$ s a segment $/ \mathrm{l} /$ in the inventory, there is no segment /i / in the inventory of Kyrghyz nor Turkish. In other words, [-back] liquids participate in harmony, but the [-back] glide does not, because there is no [+back] counterpart to the glide. The relevant property discriminating [-back] $/ 1^{\mathrm{y} /}$ and [-back] /j/ for harmony is contrastiveness:

A segment $\mathrm{S}$ with specification $\alpha \mathrm{F}$ is contrastive for $\mathrm{F}$ if there is another segment $\mathrm{F}^{\prime}$ in the inventory that is featurally identical to $\mathrm{S}$, except that it is $-\alpha \mathrm{F}$

The reason that the feature [-back] of Turkish / $\mathrm{j} /$ is not contrastive according to (22) is because / $\mathrm{j} /$ is [-vocalic] and has no [+back] counterpart. There are a number of arguments in Levi (2004) that the Turkish glide is demonstrably non-vocalic. One source of evidence for the [-vocalic] status of glides in Turkish is allomorph selection for consonant-final stems. The genitive affix varies in form for C-final (23a) vs. V-final (23b) stem. Importantly, it takes the C-final form when the stem ends in a glide $(23 \mathrm{c})$.

Turkish glide is [-vocalic] in allomorph selection:
a. jilan-i 'his snake'
b. boru-su 'his pipe'.
c. saraj-i 'his palace'.

The evidence points to the conclusion that the Turkish and Kyrghyz palatal glide is represented as follows:

$$
\text { Featural composition: [-vocalic, -cons, +sonorant, +high, -back, -round] }
$$

In developing the argument that glides are [-vocalic], we follow the general value-parameterized approach to whether or not intervening segments will be transparent that was developed by Calabrese (1995). Calabrese posited that a phonological process may be relativized to all values of a feature, only the contrastive values of a feature, or only the marked values of a feature. Turkic palatal harmony falls into the second category: glides are [-vocalic] and their feature [-back] is non-contrastive, as opposed to vowels.

Given the representation in (24), and the definition of contrastiveness in (22), we arrive at an argument for why glides do not participate in vowel harmony: because they are [-vocalic], and there is no corresponding [-vocalic] segment in the inventory that is [+back]. Lacking $[ \pm$ back] contrastiveness, glides will not participate in Turkic vowel harmony. On the other hand, the liquid $1^{\mathrm{y}}$ does have a [+back] counterpart, and so does participate in harmony. Crucially, neither the glide nor the liquid are in syllable-nuclear position, and thus the argument is that the behavior of glides in vowel harmony can only be captured by a subsegmental property: its value for the feature $[ \pm$ vocalic $]$. 


\section{Derived glides: a syllabically conditioned change to $[-$ voc $]$}

The previous section discussed the difference between glides and vowels in terms of the feature $[ \pm$ vocalic $]$. We have demonstrated that the view that syllabic position alone differentiates /i/ and /j/ (e.g. Clements and Keyser, 1983; Kaye and Lowenstamm, 1984; Rosenthall, 1994) cannot account for the different behavior of vowels and glides in [back] harmony in Turkish. ${ }^{6}$ In addition, we have demonstrated that a featural representation grouping glides together with consonants allows one to state rules of deletion and allomorphy in a straightforward manner.

One question that naturally arises regards cases of glide/vowel alternations, triggered by resyllabification. Our basic proposal is that a vowel-to-glide alternation requires a change from [+vocalic] to [-vocalic], as triggered by a syllable-position constraint:

$$
\begin{aligned}
& \text { Inviolable constraint against [+vocalic] in a Syllable Margin: } \\
& *[+\mathrm{voc}] \text { / in Margin }
\end{aligned}
$$

We assume that syllabification and resyllabification are driven by sonority sequencing. As a result, instances of vowel-vowel sequences will often trigger resyllabification, in which a vowel is placed in a non-nuclear position, as can be seen for example in the following Spanish phrases:

\section{Vowel-to-Glide Resyllabification in Spanish:}

a. mi ultima $\rightarrow$ mjultima 'my last'

b. $\quad$ tengo hipo $\rightarrow$ teygwipo 'I have hiccups'

While we cannot offer a complete account of resyllabification in vowel sequences, especially since there are a variety of outcomes, we assume that the phonological representation of the prevocalic glides in (26) is [-vocalic] as a subsequent featural change required by their placement outside of a nucleus. ${ }^{7}$

\section{Derivational sequence of Vowel-to-Glide Alternations: \\ a. Resyllabification of [i] or [o] to onset position \\ b. Result violates $*[+\mathrm{voc}] /$ in Margin \\ c. Repair: change to $[-$ voc $]$.}

The repair operation in (27) is a syllabic-position-conditioned featural change. Framed as such, it suggests that there is no especially privileged relationship between $/ \mathrm{i} / \mathrm{and} / \mathrm{j} /$, other than the fact that the repair to (25) is accomplished by changing [ \pm vocalic]. However, we might expect that, given the separation of the triggering constraint and its repair, there might be other possible featural changes that could satisfy (25) and yet yield other surface manifestations of an underlying glide.

\footnotetext{
${ }^{6}$ In addition, the existence of [-vocalic] as a subsegmental component of glides allows one to account for cases in which a glide may appear in distinct syllabic positions, but retains the same phonetic identity. For example, Tranel (1987) discusses the fact that French [wa]-initial words take the definite article allomorph l' (e.g. l'oiseau [lwazo] 'the bird') but that [wi]-initial words take the definite article allomorph le (e.g. le whisky [lœwiski] 'the whiskey'). Similar facts hold for Italian [wo]-initial words, e.g. l'uovo 'the egg' vs. il wiski 'the whiskey'. Following Tranel (1987) and Calabrese (2005), we adopt the proposal that [wa]-sequences in French and [wo]-sequences in Italian have a representation with the glide in the nucleus, thus patterning with onsetless syllables for the purposes of definite article allomorph selection, whereas the other w+vowel sequences have the glide in the onset. Importantly, the identity of these glides in the two cases can be captured in the current proposal, since they are [-vocalic] independently of syllabic position.

${ }^{7}$ Interestingly, the fact that the resyllabified mid vowel in (25) becomes a [w] (rather than, for example, o (see Hualde et al., this volume for detailed discussion of these facts) suggests that in addition to a change from [+voc] to [ - voc], the resulting [-voc, - cons, - high, +round, +back] segment also undergoes a change to [+high], arguably due to a constraint against $[-$ voc, - cons, - high $]$ segments in these speakers' grammars.
} 
Thus, the claim is that some glides may be underlyingly [-vocalic], such as Turkic / $\mathrm{j} / \mathrm{discussed}$ in section 3, while other glides may be the result of resyllabification of an underlyingly [+vocalic] vowel that undergoes a later featural change. The resulting theory is one in which a surface phone may have distinct underlying sources. Confirmation for this theory comes from cases in which we see the same surface glide behaving differently, depending on whether it comes from a lexical glide or a lexical vowel (see Levi, this volume for extended discussion of cases).

For example, in languages such as Karuk (Bright, 1957; Herman, 1994; Levi, this volume), a wide range of phonological processes distinguish underlying glides from derived glides. As Herman (1994:233) concludes, "Karuk has two phonetically identical but phonologically distinct labial glides". A number of phonological processes treat [+vocalic] elements distinctly from [-vocalic] elements, for example, a deletion process that eliminates the middle of three $[+$ vocalic $]$ elements in a row, as in $(27 \mathrm{c})$ :

$$
\begin{aligned}
& \text { Karuk contrast between underlying and derived glides } \\
& \text { a. /ikyiw+išrih } \rightarrow \text { [ikyiwišrih] 'to fall down'. } \\
& \text { b. /piu+kara } \rightarrow \text { [pi:wkara] 'to step out over' } \\
& \text { c. } \quad / \text { piu+išrih } / \rightarrow \text { [pi:šrih] 'to step down' }
\end{aligned}
$$

The glide in (28a) is underlyingly [-vocalic] and does not delete. By contrast, the glide in (28b and c) is underlyingly [+vocalic] and deletes when in a sequence of three [+vocalic] elements. Herman (1994) presents a number of similar contrasts and concludes that the surface glides in (28a)-(28b) arise from distinct underlying sources; in the present model, the latter is underlyingly $[+\mathrm{voc}]$ and only converted to $[-\mathrm{voc}]$ at a later stage of the derivation than the rule of vowel deletion operative in (28c). Importantly, Herman (1994) shows that this underlying [-vocalic] glide is transparent to vowel harmony across it, with the vowel-copying suffix $V$ wra $\theta$. In (29d), a stem independently concluded above to end with an underlyingly [-voc] glide, the glide does not inhibit vowel harmony across it:

$$
\begin{aligned}
& \text { Karuk [-voc] glide is transparent to vowel harmony: } \\
& \text { a. taxarap-awra } \theta \text { 'to stride over' } \\
& \text { b. ifkuk-uwra ' to climb over' } \\
& \text { c. ikxip-iwra } \theta \text { 'to fly over' } \\
& \text { d. ikyiw-iwra } \theta \text { 'to fall over' }
\end{aligned}
$$

Thus, the argument that glides may be either underlyingly [-vocalic] and remain so throughout the derivation, or [+vocalic] vowels that are converted to glides due to (25), is borne out by cases in which languages minimally contrast these two representations with the same surface segment.

An important aspect of (25), as formulated, is the prediction that there is no especially privileged relationship between vowels and glides at all, other than the fact that changing $[ \pm$ vocalic] is often the "cheapest" repair, as it involves only a single feature. However, we might expect that in some languages, (25) can be resolved by other repairs. Akinlabi (2007) shows that in Yoruba, high vowels in onsetless syllables may become nasal consonants:

Vowel/nasal alternations in Yoruba:
a. àwó ì wó tã́ $\rightarrow$ àwó ỳ wó tấ
"that which flows without end"

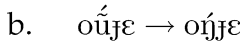
"foodstuff" 
Akinlabi (2007) argues that denuclearization to nasal consonants is one way that is compliant with sonority theory to satisfy constraints against onsetless syllables that follow vowel-final syllables. On the current model, the change would be not only to [-vocalic] but to [+nasal] as well. ${ }^{8}$ These type of alternations provide further evidence that the existence of vowel/glide alternations are not evidence for an underlying featural identity between the two. The vowel/nasal alternation in Yoruba shows that, while devocalization to a glide is one of the most economical featural repairs to vowels, as it changes [+vocalic] alone, and thereby one of the most common options cross-linguistically, it is not the only possible featural change to vowels in syllable margins to satisfy (25).

\section{Place of articulation alternations}

“La consonnantification de u. . . se produit de différentes manières ... Si l'articulation des lèvres, c'est-à-dire l'élément labial prévaut, il se produit un v ou une f; . . S Si, au contraire, c'est l'articulation vélaire qui l'emporte, u passe à g,k” (Meyer-Lübke, 1890:257). ${ }^{9}$

Our goal in this section is to demonstrate that glides have two places of articulation, based on alternations with consonants. We embrace the general Articulator model in which segments are represented with one or more Designated place of articulation. Thus far, we have concluded that the crucial glide/vowel distinction is [ \pm vocalic]. In this section, we begin with a comparison with another recent model, that of Halle (2005), who, extending revised articulator theory (Halle et al., 2000), argues that the crucial vowel/glide distinction is one of Place of Articulation (PoA): that all vowels have [Dorsal] as their designated articulator, while no glides have [Dorsal] as their designated articulator. Rather, in this model, /j/ has [Coronal] as its designated articulator, while / w/ has [Labial].

The immediate prediction of Halle's (2005) model is that there can be no Dorsal glides, as the only way of distinguishing glides from vowels is the former's lack of [DA: Dorsal]. This approach is falsified by the existence of unrounded velar glides: [u]. as in Korean [uiza], 'doctor' and [uidza] 'chair'. This segment is unrounded, hence cannot be [Labial] (and is also distinct from a velar fricative (Martínez-Celdrán, 2004)). The existence of this [-vocalic, - consonantal] segment whose primary articulation is Dorsal is well-documented in Korean, as described in the following passage:

"In word-initial position the vowel [i y] is seldom realized as the off-glide diphthong [i y], either, whose nucleus is the high central unrounded vowel ut but rather occurs in a new diphthongal form consisting of a high central unrounded on-glide followed by the high front nucleus [i], i.e., [ui], which we shall represent phonemically as /uil using the IPA symbol [u] to stand for this third kind of on-glide". (Ahn and Iverson, 2006:11)

There is also discussion in the literature of the velar glide of Axininca Campa (Black, 1993; Spring, 1993). We thus propose the following representations for the PoA of various glides (the corresponding vowels are $[+$ vocalic]):
a. w: [Dorsal, Labial] [-vocalic]
b. j: [Dorsal, Coronal] [-vocalic]
c. u: [Dorsal] [-vocalic]
d. y: [Dorsal, Labial, Coronal] [-vocalic]

\footnotetext{
${ }^{8}$ The fact that resulting consonants have a Dorsal place of articulation will be understandable by the end of the next section, as we argue that vowels and glides contain a [Dorsal] articulation.

${ }^{9}$ The consonantalization of $\mathrm{u}(=\mathrm{w})$ can be realized in different ways. If the articulation of the lips, that is, the labial element prevails, it produces a [v] or an [f]. If, on the contrary, it is the velar articulation that takes over, $\mathrm{u}_{(\mathrm{f}}(=\mathrm{w})$ becomes [g,k] (authors' translation).
} 
The representations in (31) are ones in which glides may contain multiple Designated Articulators. This has already been phonetically shown by Keating (1988) for /j/ and Gick (2003) for $/ \mathrm{w} /$, and we turn shortly to phonological alternations. The resulting model thus represents a synthesis of two different feature-geometry proposals: Sagey (1986), in which vowels and front glides contain [Dorsal], and Clements (1991), in which front glides contain [Coronal]. An important prediction of (31) is that when glides alternate with consonants, they may show up as potentially either of their subcomponent articulators.

An important inviolable constraint (not active in all languages) bans [+cons] segments with more than one Designated Articulator, represented by the following feature co-occurrence statement:

$$
*[|D A|>1,+ \text { cons }]:
$$

The prediction of the constraint in (31) is that if glides become [+cons], they will have to lose one of their Designated Articulators. ${ }^{10}$ We turn to a few case studies bearing this out.

In Cypriot Greek (Newton, 1966; Kaisse, 1992; Papanicola, 2005), the glide turns into [k] when after a consonant from the set $[\mathrm{p}, \mathrm{t}, \mathrm{f}, \mathrm{v}, \theta, \mathrm{\partial}, \mathrm{f}]$, with representative examples shown in (33). ${ }^{11}$

The dorsal $[\mathrm{k}]$ has both [+back] and [-back] allophones (and we remind the reader that, following Sagey (1986), the feature [-back] is distinct from and independent of [Coronal]). The [+back] allophone is found after / $\mathrm{r} /$ and the [-back] allophone, denoted as [ $\mathrm{k}]$ following Kaisse, is found elsewhere.

Cypriot Greek postconsonantal glides surface as Dorsal stops:
a. aðerfi 'brother'
/aðerfi $+\mathrm{a} / \rightarrow$ aðerfja $\rightarrow$ aðerfka 'brothers'
b. zefkari 'couple'
/zefkari+a/ $\rightarrow$ zefkarja $\rightarrow$ zefkarka 'couples'
c. vari 'heavy'
var + ume $\rightarrow$ varjume $\rightarrow$ varkume 'I am bored'
d. mmati 'eye' mmati $+\mathrm{a} \rightarrow$ mmatja $\rightarrow$ mmatka $\rightarrow$ maӨka 'eyes'
e. pi-nno 'I drink'
na pi o $\rightarrow$ napjo $\rightarrow$ napko or nafko 'that I drink'

In Standard Greek, these postconsonantal and prevocalic vowels surface as glides. By contrast, in Cypriot Greek, postconsonantal glides surface as Dorsal stops. This is specifically in postconsonantal contexts and is not due to a general rule of Cypriot Greek targeting onset glides, cf. (34).

\footnotetext{
${ }^{10}$ The constraint (32) does not refer to terminal features such as $[ \pm$ anterior $],[ \pm$ distributed $],[ \pm$ back $]$, which are not Designated Articulator features. These terminal features may persist despite the repairs to (32). In the case of Cypriot Greek, for example, the feature [-back] of /j/ is retained even when its [Coronal] feature is removed.

${ }^{11}$ The outcomes of a glide following the other consonants of Cypriot Greek are as follows (Spyros Armosti, personal communication):

(i) a. $/ \mathrm{mj} / \rightarrow[\mathrm{mp}]$

b. $/ \mathrm{nj} / \rightarrow[\mathrm{n}:]$

c. $\quad / \mathrm{lj} / \rightarrow\left[\lambda_{\mathrm{i}}\right]$ or $[\mathrm{j}:]$

d. $/ \mathrm{kj} / \rightarrow[\mathrm{t} f]$ or $[\mathrm{k}]$

e. $/ x \mathrm{x} / \rightarrow\left[\int\right]$ or $[c ̧]$

f. $/ \mathrm{\gamma j} / \rightarrow[\mathrm{j}]$

g. $/ \mathrm{sj} / \rightarrow\left[\int\right]$

h. $/ z j / \rightarrow\left[3^{\star}\right]$

i. $/ \widetilde{\mathrm{tsj}} / \rightarrow\left[\mathrm{t}^{\mathrm{h}}\right]$
}

Notice that the outcome of all of these changes is a coronal segment, while the outcome of the changes in the text is a dorsal segment. 
(34) Cypriot Greek onset glides surface intact ${ }^{12}$ :
a. jerakos 'falcon'
b. loja 'words'
c. čai 'tea', čai+a $\rightarrow$ čaja 'teas'

When either an obstruent or a continuant sonorant precedes a glide, it induces a subsegmental spreading of [+cons] to the glide in (33). By virtue of being in onsets, these glides are already [-voc]. According to Kaisse, the feature [+cons] spreads. The constraint in (32) demands simplification of the result.

Now, why all the other changes? Kaisse argues that there is a continuancy template, requiring that consonant sequences must have a [-cont] stop as their second member. Moreover, underlyingly, Cypriot Greek has no voiced stops (or $/ \mathrm{w} /$ ). The result is a [-back] Dorsal consonant which is [-voice, -cont]: [k] (except after [r], where it is [k]).

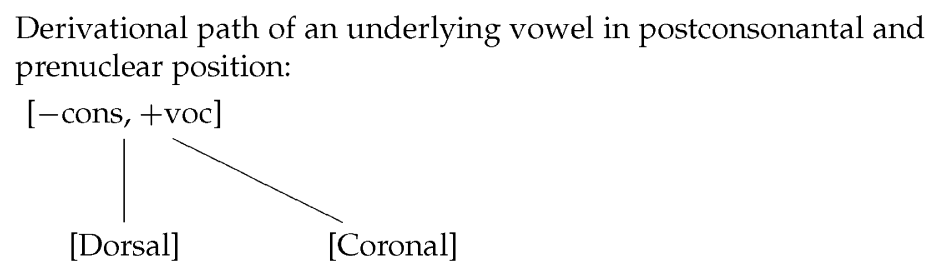

(then by (25) ...)

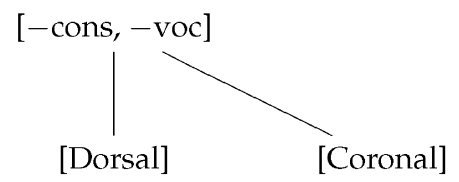

(then by SPREADING of [+cons] ...)

[+cons, -voc]

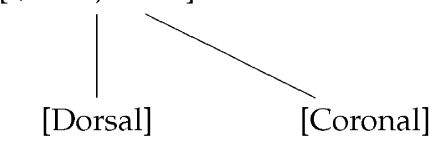

(then by *2DA,+CONS ...)

[+cons, -voc]

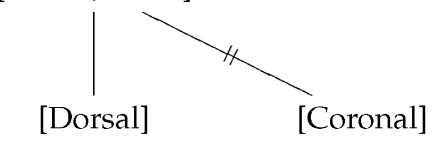

(then by ${ }^{*}+$ CONT / C_...)

[+cons, -voc, -cont]<smiles>C=CC</smiles>

[Dorsal]

\footnotetext{
${ }^{12}$ These onset glides may strengthen to the [+distributed, - anterior, - strident] Coronal fricative $j$ in onset position, though they clearly come from an underlying /i/ and by hypothesis an intermediate / $\mathrm{j} /$.
} 
Thus, Glides alternate with Dorsal consonants. A second example of the same alternation comes from Bergüner Romansh (Kamprath, 1987; Kaisse, 1992), involving spread of [+cons] from an adjacent consonant (36):

Bergüner Romansh preconsonantal glides become Dorsal stops:
a. kreja 'believes'
$/ \mathrm{krej}+\mathrm{r} / \rightarrow \mathrm{krekr}$
b. Ždreja 'destroys'
ždrekr 'to destroy'
c. /la bijza / $\rightarrow$ la bigza 'snowstorm'
d. German bauer 'peasant' $\rightarrow$ pogra, pokr
e. /lavowr+a/ $\rightarrow$ lavogra 'works'
(cf. /lavowrér/ $\rightarrow$ lavurer, inf.)

There is no general process of glide consonantalization in coda position:

Bergüner Romansh non-preconsonantal glides surface intact:
a. laj 'lake'
b. dzej 'juice'

The fact that (a) Bergüner glide hardening is conditioned by [+cons] context on the right whereas in Cypriot Greek it is on the left and (b) occurs with /w/ as well as /j/ confirms the generality of the derivation in $(35)$. $^{13}$

Importantly, while the glide/velar alternations above show simplification to [Dorsal] only, there is always more than one way to resolve (32). Indeed, in Argentinian Spanish, the glide /j/ alternates with the coronal fricative [3] in onsets (Harris and Kaisse, 1999:146):

$$
\begin{aligned}
& \mathrm{j} / 3 \text { alternations in Argentinian Spanish } \\
& \text { a. [uruguaj, uruguazo] } \\
& \text { b. 'Uruguay, Uruguayan' } \\
& \text { [lej, lezes] } \\
& \text { 'law, laws' }
\end{aligned}
$$

We analyze this alternation as a change in major class features conditioned by syllable position. ${ }^{14}$

$$
\text { Consonantalization of } / j / \text { to coronal fricative }
$$
a. $[-$ cons $] \rightarrow[+$ cons $]$ in Onset
b. Repair to (32): Delink [Dorsal]
c. Result: [+cons,-ant, Coronal]: [3]

\footnotetext{
${ }^{13}$ Cho and Inkelas (1993) offer a reanalysis of the Cypriot Greek and Bergüner Romansh facts in which [+consonantal] (or in our case, [-vocalic]) is inserted according to moraic or syllabic position, as opposed to spreading autosegmentally. Should this analysis turn out to be preferable on empirical or theoretical grounds, it affects only the first step of the derivation (in which the glide's major class feature undergoes a change), and the crucial subsequent steps of Articulator simplification would remain the same in our analysis.

${ }^{14}$ Hume and Odden (1996) offer an alternative to use of [ \pm consonantal] (or [ \pm vocalic]) for glide/consonant alternations in Cypriot Greek, Bergüner Romansh, and Argentinian Spanish. In their analysis, the relevant features undergoing changes are either [continuant] or [sonorant]. In avoiding the involvement of [ \pm consonantal], however, this alternative fails to capture what appears to us to be the apparent unity of these processes and their restriction to glide targets.
} 
This confirms that $/ \mathrm{j} /$ is [Coronal] as well as [Dorsal]. Additional evidence of alternation between [-cons] high segments and coronal fricatives comes from Uyghur (Hahn, 1991; Kaisse, 1992) and probably many other languages (in fact, according to Spyros Armosti (personal communication, April 2007), the Paphos dialect of Cypriot Greek is said to consonantalize / $\mathrm{j} /$ to coronal [ $\left.\int\right]$ instead of dorsal $[\mathrm{k}])$.

In fact, the proposal that $/ \mathrm{j} /$ is both [Coronal] and [Dorsal] allows one to understand not only fortition processes in which the palatal glide strengthens to [k], but also processes of the reverse nature, such as lenition. For example, in the development from Vulgar Latin to Western Romance, a preconsonantal [k] became a [j]; cf. nocte $>$ noite (Portuguese), and many other examples. For (Clements, 1991:98), for whom palatal glides are [Coronal] only " $[\mathrm{k}]$ and [g] weaken to the palatal glide in apparent contradiction to our predictions . . . this development should probably be regarded as idiosyncratic". However, this pattern is by no means limited to Romance; Jay Jasanoff (personal communication, August 2007) reports that from Celtic to Welsh, the same pattern of preconsonantal $\mathrm{k}$-weakening occurred, e.g. lact $>$ llaith'milk'. This process is easily modeled as dissimilation, given the features $[ \pm \mathrm{cons}, \pm \mathrm{voc}]$ and the proposal that glides are [Dorsal].

$$
\begin{aligned}
& \text { Preconsonantal change of dorsal stops to }[- \text { cons }] \text { : } \\
& \text { a. Consonantal dissimilation: }[+ \text { cons, }- \text { voc }] \rightarrow[- \text { cons, }- \text { voc }] \\
& \text { before }[+ \text { cons, }- \text { voc }] \\
& \text { b. Result: }[- \text { cons, }- \text { voc, Dorsal }]
\end{aligned}
$$

The representation in (40b) corresponds to a glide. As Western Romance lacks the unrounded Dorsal glide, the representation in (40b) must be repaired by feature epenthesis, either of [Coronal] or [Labial]. (By contrast, /k/-weakening in Maxakalí (Gudschinsky et al., 1970) yields u). In Western Romance, the repair operation is insertion of [Coronal], yielding / $\mathrm{j} /$.

We turn to evidence that [w] is [Labial] as well as [Dorsal]. First, in varieties of Spanish, /w/ strengthening can yield $\mathrm{g}^{\mathrm{w}}, \mathrm{\gamma}^{\mathrm{w}}$, e.g. weßo $\sim \gamma^{\mathrm{w}} \mathrm{e} \beta \mathrm{o}, \mathrm{g}^{\mathrm{w}}$ eßo 'egg' (Navarro-Tomás et al., 1970).

Finally, there is evidence that /w/ is [Labial], as it may consonantalize to [Labial] in Karuk in preconsonantal position (Bright, 1957; Herman, 1994; Levi, this volume). Herman (1994: 240) specifically mentions this process does not occur in final coda position.

Glide/nasal alternations in preconsonantal position (Karuk):
a. [?ápiw] 'seek'
/apiw / $\rightarrow$ [?ápim-tih] 'to be seeking'
b. [?ásiw] 'sleep'
/asiw/ $\rightarrow$ [?ásim-t $\left.\int a k\right]$ 'to close one's eyes'

(42) Glide consonantalization in preconsonantal position:
a. [-cons $]$ to $[+$ cons $] /{ }_{-} \mathrm{C}$
b. Repair to (32): Delink [Dorsal]
c. Result: [+cons, Labial]: [m]

We can understand the cases in which, for example, /w/ alternates with a [Labial] (as in Karuk above) and in which it alternates with a [Dorsal] (as in Romansh above) as different simplifications of a complex articulation. Indeed, in the analysis of Fula /w/ alternations between either [Labial] [b] or [Dorsal] [g], Anderson (1976) advances a similar proposal, that [w] "has two distinct characterizations: as a labialized velar and as a velarized labial. The two are phonologically distinct ... but may well be phonetically indistinguishable" (p. 130). While Anderson's proposal is in terms of preservation of the primary articulator of a secondarily 
articulated consonant and ours is in terms of a symmetrically doubly articulated consonant that is asymmetrically simplified, the essential insight is that the variable consonantalization of glides results from a complex representation in which they have more than one articulator.

Further research may reveal that going for one or the other of these types of simplifications may be predictable on the grounds of environment, and this is a further and important direction of this research, which we discuss in section 6.

\section{Articulatory correlates of multiple articulators for glides}

The overall behavior of glides as containing both a consonantal representation and a vocalic representation, and both a Dorsal articulation and a Coronal $(/ \mathrm{j} /)$ or Labial $(/ \mathrm{w} /)$ articulation is consistent with what we know to be the gestural composition of glides, due to articulatory (magnetometer) studies by Gick (1999a, b, 2003). Gick has shown that the glide /w/ in American English consists of two gestures, one vocalic (the tongue dorsum raising gesture) and one consonantal (the lip constriction gesture). The exact terms proposed by Gick are V-gesture and $\mathrm{C}$-gesture, respectively. The defining properties of a $\mathrm{C}$-gesture are experimentally determined as: (1) final reduction, (2) intermediate magnitude under resyllabification, and (3) tendency to occur farther from the nucleus vowel. Gick incorporates these results in a phonological analysis in the framework of Articulatory Phonology (Browman and Goldstein, 1992). While the composition of the palatal glide / $\mathrm{j} /$ is less clear, since relatively few cross-linguistic studies have been done so far, we will proceed with the hypothesis that $/ \mathrm{j} /$ also consists of a vocalic, tongue body gesture and a consonantal, arguably tongue blade gesture.

These findings in turn allow us to further propose the following experimentally testable hypothesis: if glides involve two gestures, the cross-linguistic distinction between vocalic and consonantal behavior may be reflected phonetically in the relative magnitude of one or the other of the two gestures. In other words, the cross-linguistically variable behavior of glides may result from the relative magnitude of vocalic and consonantal gestures. Thus, the glides with a relatively larger dorsal gesture would alternate with dorsals, and the glides with a relatively larger non-dorsal gesture would alternate with non-dorsal consonants. According to this hypothesis, Fula would have two phonetically distinct glides, following the intended spirit of Anderson's (1976) proposal. We propose that the ones with a relatively larger dorsal gesture alternate with [g], and the ones with the relatively larger non-dorsal gesture alternate with [d3] and [b], respectively. In many cases glides with a larger dorsal gesture are underlyingly [+vocalic], and converted to [-vocalic] via the syllable-margin feature change in section $4 .{ }^{15}$ For example, we see underlyingly [+vocalic] glides alternating with velar stops in Cypriot Greek, Fula and Bergüner Romansh.

The Cypriot Greek glides alternate with two allophones of velar stops, one fronted, one back. The fronted allophone is the result of the blending of the two articulatory gestures, the dorsal and coronal, while the back allophone is apparently conditioned by the specific gesture of the preceding rhotic. At least for American English bunched and retroflex /r/ we know that it includes a pharyngeal, tongue root retraction gesture (Delattre and Freeman, 1968; Narayanan et al., 1997; Gick, 1999a). The fact that Cypriot Greek /r/ conditions the back allophone suggests that it also includes such a gesture, if tongue root retraction can lead to tongue body retraction.

\footnotetext{
15 That the designated articulator is [Dorsal] for vowels has been proposed in Sagey (1986) and Howe (2004).
} 
The data from glide alternations in Fula are particularly interesting, since Fula / $\mathrm{j} /$ and $/ \mathrm{w} /$ participate in two types of alternations. The alternations are triggered at the word-initial position of noun stems by suffixal markers of the 2 nd degree (also called the "stop grade"; used for plural marking).

$$
\begin{aligned}
& \text { Fula (Paradis, 1987, 331-332): } \\
& \text { a. } \quad \mathrm{j} \rightarrow \mathrm{d}_{3}: \quad \text { ju66-o } \rightarrow \text { d3u66-e 'system; degree 1, degree 2' } \\
& \mathrm{w} \rightarrow \mathrm{b} \text { : wil-de } \rightarrow \text { bil-e 'trap; degree 1, degree } 2 \text { ' } \\
& \text { b. } \quad \mathrm{j} \rightarrow \mathrm{g} \text { before } / \mathrm{i}, \mathrm{e} / \mathrm{g} \quad \text { jit-ere } \rightarrow \text { git-e 'eye; degree } 1 \text {, degree } 2 \text { ' } \\
& \mathrm{w} \rightarrow \mathrm{g} \text { before /u,o/: } \quad \text { wor-du } \rightarrow \text { gor-i 'thumb; degree } 1 \text {, degree } 2 \text { ' }
\end{aligned}
$$

Based on historical evidence from Klingenheben (1927), Paradis (1987) assumes that the forms in (43-b) began with a velar glide ${ }^{*} \mathrm{\gamma}$, which was subsequently lost. ${ }^{16}$ In Paradis' analysis the empty onset is synchronically filled by spreading from the nucleus vowel, hence the homorganicity of the onset glide and nucleus vowel. This analysis allows Paradis to consider the glides in (43a) 'consonantal', and those in (43b) 'vocalic', a division that has been adopted by subsequent researchers (see Levi, 2004). In our analysis the glides in (43a) are phonemically [-vocalic]. We predict that in alternations their consonantal (coronal or labial) gesture will predominate. The glides in (43b) are derived by spreading from the adjacent vowel, so we predict that in alternations their vocalic (dorsal) gesture will predominate. We hope that the basis for this hypothesis will continue to be tested cross-linguistically with further articulatory studies.

In summary, while the constraint in (32) does not demand a specific repair, the interface of abstract phonological representations with an articulatory-phonetic decomposition of speech segments into more consonant-like and more vowel-like component gestures may lead to a predictive account of when (32) will be resolved in favor of which articulation.

\section{Conclusion}

The variable patterning of glides derives from the fact that (a) they share features in common with both vowels and consonants and so may pattern with either, and (b) that they bear more than one Place of Articulation, so may alternate with various consonants. This demonstrates yet another case of the importance of the interaction of rich representations and phonological derivations in understanding varied phonological patterning and ideally will provide inspiration for more research into the typology of glide/consonant alternations.

\section{Acknowledgements}

We would like to thank Spyros Armosti, Eric Bakovic, Andrea Calabrese, Nick Clements, Morris Halle, José Ignacio Hualde, Jay Jasanoff, Victor Manfredi, John Moore, David Odden, Sharon Rose, and Bert Vaux for their input and feedback, most of which we have been able to incorporate in the current paper.

\footnotetext{
${ }^{16}$ See (Anderson, 1976:114-116) for an overview of the consequences of this change in varieties of Fula; for example, Western Fula replaced ${ }^{*} \mathrm{y}$ by $\mathrm{y}, \mathrm{w}, ?$ in front of $\mathrm{i} / \mathrm{e}, \mathrm{u} / \mathrm{o}$, and a, respectively, whereas Eastern Fula (which includes the varieties studied by Paradis) did not innovate a glottal stop before [a]; cf. am-re $\sim$ gam-e 'turtle' (Paradis, 1987:335).
} 


\section{References}

Ahn, S.-C., Iverson, G.K., 2006. Structured imbalances in the emergence of the Korean vowel system. In: Salmons, J.C., Dubenion-Smith, S. (Eds.), Historical Linguistics 2005: Selected Papers from the 17th International Conference on Historical Linguistics, Madison, 31 July-5 August 2005. John Benjamins, Amsterdam/Philadelphia.

Akinlabi, A., 2007. Category change as vowel reduction. Paper Presented at GLOW 30, Troms $\emptyset$.

Anderson, S., 1976. On the description of consonant gradation in Fula. Studies in African Linguistics 7.1, 93-136.

Bailey, C.-J.N., Milner, J.-C.G., 1967. The major class features 'sonorant' and 'vocalic' and the problem of syllabicity in generative phonology with a note on the feature 'high'. Ms, MIT (ERIC/Pegs Paper no 19, Washington DC, 1968).

Bailyn, J., Nevins, A., 2007. Russian genitive plurals are impostors. In: Inflectional Identity. Oxford University Press.

Bateman, N., 2007. A crosslinguistic investigation of palatalization. Doctoral Dissertation. UC, San Diego.

Black, A., 1993. The phonology of the velar glide in Axininca Campa. Phonology 8, 183-217.

Bright, W., 1957. The Karok Language. University of California Press.

Browman, C.P., Goldstein, L., 1992. Articulatory phonology: an overview. Phonetica 49, 155-180.

Calabrese, A., 1995. A constraint-based theory of phonological markedness and simplification procedures. Linguistic Inquiry 26, 373-463.

Calabrese, A., 2005. Markedness and Economy in a Derivational Model of Phonology. Mouton de Gruyter.

Cho, Y., Inkelas, S., 1993. Major class alternations. WCCFL 12, 3-18.

Chomsky, N., Halle, M., 1968. The Sound Pattern of English. Harper and Row.

Clark, J., Yallop, C., 1995. An Introduction to Phonetics and Phonology. Blackwell Publishers.

Clements, G.N., 1991. Place of articulation in consonants and vowels: a unified theory. Working Papers of the Cornell Phonetics Laboratory 5, 77-123.

Clements, G.N., Hume, E., 1995. The internal organization of speech sounds. In: Goldsmith, J. (Ed.), The Handbook of Phonological Theory. Blackwell, pp. 245-306.

Clements, G.N., Sezer, E., 1982. Vowel and consonant disharmony in Turkish. In: The Structure of Phonological Representations, Part II. Foris, Dordrecht, pp. 213-255.

Clements, G.N., Keyser, S.J., 1983. CV Phonology: A Generative Theory of the Syllable. MIT Press.

Delattre, P., Freeman, D.C., 1968. A dialect study of American $r$ s by X-ray motion picture. Linguistics 44, 29-68.

Gick, B., 1999a. A gesture-based account of intrusive consonants in English. Phonology 16, 29-54.

Gick, B., 1999b. The articulatory basis of syllable structure: a study of English glides and liquids. Doctoral Dissertation. Yale University.

Gick, B., 2003. Articulatory correlates of ambisyllabicity in English glides and liquids. In: Local, J., Ogden, R., Temple, R. (Eds.), Phonetic Interpretation: Papers in Laboratory Phonology IV. Cambridge University Press, pp. $222-236$.

Gudschinsky, S., Popovich, H., Popovich, F., 1970. Native reaction and phonetic similarity in Maxakali phonology. Language 46, 77-88.

Hahn, R., 1991. Diachronic aspects of regular disharmony in modern Uyghur. In: Studies in the Historical Phonology of Asian Languages. John Benjamins, Amsterdam, pp. 68-101.

Hall, T., Hamann, S., 2006. Towards a typology of stop assibilation. Linguistics 44.

Hall, T., Hamann, S., Zygis, M., 2006. The phonetic motivation for phonological stop assibilation. Journal of the International Phonetics Association 36.1, 59-81.

Halle, M., 1994. The Russian declension. In: Perspectives in Phonology, CSLI.

Halle, M., 1995. Feature geometry and feature spreading. Linguistic Inquiry 26.1, 1-46.

Halle, M., 2005. Palatalization/Velar softening: what it is and what it tells us about the nature of language. Linguistic Inquiry $36.1,23-41$.

Halle, M., Vaux, B., Wolfe, A., 2000. On feature spreading and the representation of place of articulation. Linguistic Inquiry $31.3,387-444$.

Harris, J.W., Kaisse, E., 1999. Palatal vowels, glides, and obstruents in Argentinian Spanish. Phonology 16, 117-190.

Herman, R., 1994. "La double vie de w" or The status of [w] in Karuk. Studies in the Linguistic Sciences 24.1, 233-244.

Howe, D., 2004. Vocalic dorsality in revised articulator theory. Paper Presented at the LSA 2004 Meeting, Boston.

Hualde, J.I., Simonet, M., Torreira, F. Postlexical Contraction of Nonhigh Vowels in Spanish, this volume.

Hume, E., Odden, D., 1996. Reconsidering [consonantal]. Phonology 13, 345-376.

Hyman, L., 1985. A Theory of Phonological Weight. Dordrecht, Foris.

Jakobson, R., 1948. Russian conjugation. Word 4, 155-167.

Jakobson, R., Halle, M., 1956. Fundamentals of Language. Mouton, The Hague. 
Johnson, C.D., 1980. Regular disharmony in Kirghiz. In: Issues in Vowel Harmony. John Benjamins, Amsterdam, pp. 89-99.

Kaisse, E., 1992. Can [Consonantal] spread? Language 68.2, 313-332.

Kamprath, C., 1987. Suprasegmental structures in a Räto-Romansh dialect: a case study in metrical and lexical phonology. Doctoral Dissertation. University of Texas, Austin.

Kaye, J., Lowenstamm, J., 1984. De la syllabicité. In: Forme Sonore du Langage. Hermann, Paris, pp. $123-159$.

Keating, P., 1988. Palatals as complex segments: X-ray evidence. UCLA Working Papers in Phonetics 69, 77-91.

Klingenheben, A., 1927. Die Laute des Ful. Zeitschrift für eingeborenen Sprachen 9. Reimer, Berlin.

Korn, D., 1969. Types of labial vowel harmony in the Turkic languages. Anthropological Linguistics 11.3, 98-106.

Kornfilt, J., 1997. Turkish. Routledge.

Ladefoged, P., Maddieson, I., 1996. The Sounds of the World's Languages. Blackwell, Oxford.

Levi, S. Phonemic vs. Derived Glides, this volume.

Levi, S.V., 2004. The representation of underlying glides: a cross-linguistic study. Doctoral Dissertation. University of Washington.

Maddieson, I. Glides and Gemination, this volume.

Maddieson, I., Emmorey, K., 1985. Relationship between semivowels and vowels: cross linguistic investigations of acoustic difference and coarticulation. Phonetica 42.4, 163-174.

Martínez-Celdrán, E., 2004. Problems in the classification of approximants. Journal of the International Phonetics Association 34.2, 201-210.

Meyer-Lübke, W., 1890. Grammaire des Langues Romanes (French translation by E. Rabiet), vol. 1. Phonétique. Welter, Paris.

Narayanan, S.S., Alwan, A.A., Haker, K., 1997. Toward articulatory-acoustic models for liquid approximants based on MRI and EPG data. Part I. The laterals. Journal of the Acoustic Society of America 101, 1064-1077.

Navarro-Tomás, T., Haensch, G., Lechner, B., 1970. Spanische Aussprachlehre. Max Hueber, München.

Nevins, A., 2004. Conditions on (dis)harmony. Doctoral Dissertation. MIT.

Nevins, A., Vaux, B., 2006. The role of contrast in locality: transparent palatal glides in Kyrghyz. In: MITWPL 54. MITWPL, Cambridge, MA, pp. 275-287.

Newton, B., 1966. Cypriot Greek: Its phonology and inflections. Mouton, The Hague.

Ohala, J., 1983. The origin of sound patterns in vocal tract constraints. In: The Production of Speech. Springer, pp. 189216.

Padgett, J. Glides, Vowels and Features, this volume.

Papanicola, E., 2005. Are phonotactics syllabically conditioned? The case of the Cypriot Greek dialect. Master's Thesis. University College, London.

Paradis, C., 1987. Glide alternations in Pulaar (Fula) and the Theory of Charm and Government. In: Current Approaches to African Linguistics. Dordrecht, pp. 327-328.

Paradis, C., 1992. Lexical Phonology and Morphology: The Nominal Classes in Fula. Garland, New York.

Poppe, R.H.N., 1963. Kirghiz Manual. Indiana University Publications in Uralic and Altaic Series.

Rosenthall, S., 1994. Vowel/glide alternation in a theory of constraint interaction. Doctoral Dissertation. UMass Amherst.

Sagey, E., 1986. The representation of features and relations in nonlinear phonology. Doctoral Dissertation. MIT.

Schane, S., 1968. French phonology and morphology. Research Monograph No. 45. MIT Press.

Spring, C., 1993. The velar glide in Axininca Campa. Phonology 9, 329-352.

Straka, G., 1964. A propos de la question des semi-voyelles. Zeitschrift fuer Phonetik Sprachwissenschaft und Kommunikationsforschung 17, 301-323.

Tranel, B., 1987. The Sounds of French. Cambridge University Press.

Vaux, B., 1993. The origins of labial attraction. In: Harvard Working Papers in Linguistics 2. HWPL, Cambridge, MA, pp. 228-237.

Wurm, S., 1949. The (Kara-)Kirgiz language. Bulletin of the School of Oriental and African Studies 13.1, 97-120. 